\title{
Urbanização costeira e sombreamento na praia de Boa Viagem, Recife-PE, Brasil ${ }^{1}$
}

\author{
Rodrigo Mikosz Gonçalves², Admilson da Penha Pacheco ${ }^{3}$, Elmo \\ Leonardo Xavier Tanajura ${ }^{4}$ e Luciana Maria da Silva ${ }^{5}$
}

\begin{abstract}
RESUMO
Parte da concentração urbana do Município de Recife, Capital do Estado de Pernambuco, na região Nordeste do Brasil, está inserida no litoral. A cidade do Recife conforme dados do censo de 2010, conta com uma população de 1.536 .934 habitantes, distribuída numa área de aproximadamente $220 \mathrm{~km}^{2}$. O presente trabalho tem como objetivo investigar a evolução do uso do solo numa área localizada na praia de Boa Viagem, onde foi realizada uma análise quantitativa da evolução urbana, considerando aspectos dos anos de 1974, 2005, 2010 e 2011. Para tanto, foram utilizadas imagens de alta resolução espacial, ortofotos e efetuado um levantamento topográfico. Os resultados obtidos são informações quantitativas que caracterizam aspectos temporais do zoneamento costeiro. Outro resultado importante foi a identificação do sombreamento num trecho da praia e a determinação da posição da linha de costa na área selecionada, sendo possível confrontá-la com a Lei de gerenciamento costeiro do Estado.
\end{abstract}

Palavras chave: Urbanização costeira, sombreamento, mapas temáticos, linha de costa.

\begin{abstract}
Part of the urban concentration at Recife municipality, capital of Pernambuco State, in Northeastern Brazil is inserted into the coastal zone. Recife according to the census data from 2010 has a population of 1.536 .934 inhabitants, distributed in an area of approximately $220 \mathrm{~km}^{2}$. This study aims to investigate the evolution of land use in an area located at Boa Viagem beach (Recife/Pernambuco/Brazil), where was realized a quantitative analysis of land use and urban zone evolution considering aspects of the years 1974, 2005, 2010 and 2011. For this purpose, were used satellite images of high spatial resolution, orthophotos and conducted a survey. The results are quantitative information that characterizes some temporal aspects of coastal zoning in Boa Viagem. Another important result was the identification of shading in a stretch of beach and the determination of shoreline position in the selected area and the comparison with the Coastal Management Act of Pernambuco State.
\end{abstract}

Key words: Coastal urbanization, shading, thematic maps, shoreline

\footnotetext{
1 Ao projeto PPP/APQ-1242-1.07/10: Monitoramento e mapeamento costeiro do uso e ocupação do solo nos municípios de Recife e Jaboatão dos Guararapes. Financiadores: FACEPE/CNPq. Artículo recibido el 25 de enero del 2012, aceptado el 9 de febrero de 2012 y corregido el 22 de junio de 2012.

2 Universidade Federal de Pernambuco (Brasil). E-mail: rodrigo.mikosz@ufpe.br
}

3 Universidade Federal de Pernambuco (Brasil). E-mail: admilpp@ufpe.br

4 Universidade Federal do Acre (Brasil). E-mail: elmo@ufac.br

5 Universidade Federal de Pernambuco (Brasil). E-mail: luciana_maria15@hotmail.com 
Desde a década de 70, os países subdesenvolvidos vêm tendo alto índice de desenvolvimento, passando por um intenso processo de urbanização. Dados do IBGE (2000) indicam que no Brasil mais de $80 \%$ da população está localizada nas áreas urbanas provocando um crescimento desordenado das áreas urbanas e inúmeros problemas socioambientais para a população residente nesses locais. Segundo Polidoro et al., (2009), o progresso das relações institucionais e informais entre as cidades, a explosão demográfica devido ao êxodo rural, o desenvolvimento econômico, contribuíram para a formação de algumas áreas metropolitanas, (Krellenberg et al., 2011) e a geração de conurbações.

O processo de conurbação é caracterizado por um crescimento que expande a cidade, prolongando seu perímetro externamente absorvendo aglomerados rurais e outras cidades. Estas, até então com vida política e administrativa autônoma, acabam comportando-se como parte integrante da metrópole.

Recife assim como a maior parte das metrópoles brasileiras cresceu através do processo de metropolização por inchação, ou seja, tem uma concentração de habitantes em nível elevado. Uma cidade em crescimento com outros núcleos urbanos a sua volta absorve e/ou gera, a conurbação, que se caracterizam não apenas pela junção geográfica espacial de cidades, mas pela interação socioeconômica entre elas.

A cidade do Recife possui grande relevância e importância econômica e cultural para a região Nordeste e para o Brasil. Sendo o destaque em qualquer um dos aspectos: demográfico, cultural, econômico, ambiental, político, institucional e patrimônio histórico.

Com a expansão e a integração das cidades, desaparecem os limites físicos entre os diferentes núcleos urbanos. Ocorrendo uma dicotomia entre o espaço edificado e a estrutura político-administrativa. O processo de urbanização acelerado acarreta alguns problemas devido à falta de infraestrutura das cidades ao receber um grande número de pessoas e demandas sociais, há ressalvas em Sánchez (2010). Essa aceleração e o não planejamento da população urbana causam muitos problemas sociais e ambientais (Novack \&
Kux, 2010), tais como: congestão de tráfego, acúmulo de lixo, poluição do ar, inundações (Amaral \& Ribeiro, 2009), deslizamento (Tominaga, 2009), falta de água ou de espaço e quando se trata de área costeira a erosão costeira, mais detalhes em (Boak \& Turner, 2005; Hapke \& Plant, 2010).

O município do Recife tem uma ampla área litorânea, mas vem sofrendo modificações ao longo do tempo. Neste contexto, na busca pela resposta a estas questões deparase com um dos problemas do crescimento vertiginoso do Recife: a ocupação irregular (assentamentos subnormais) em geral pela população de baixa renda que proliferam em áreas muitas vezes de proteção ambiental.

Os assentamentos subnormais estão sempre em constantes modificações, sendo de extrema importância o mapeamento dessas áreas para quantificar os habitantes e desenvolver as análises das degradações e evoluções das mesmas como ferramentas de auxílio no planejamento urbano, há mais detalhes em Teixeira \& Heller (2005), além do combate de processo erosivo em áreas de risco (Hapke \& Plant, 2010).

Aspectos ligados à urbanização em áreas costeiras tem sido alvo de investigações em diversos países da América Latina e do mundo. Estudos realizados em 18 localidades balneárias no extremo norte da costa atlântica argentina demonstraram que a urbanização costeira turística contribuiu para mudanças drásticas na vegetação local, onde uma grande variedade de espécies da flora foram inserida nessas localidades oriundas de outras regiões (Faggi \& Dadon, 2010). Alguns efeitos da verticalização em praias da cidade de Atlantic City, New Jersey, USA, são verificados por Nordstrom \& Jackson (1998). Os resultados revelam que os edifícios de grande porte construídos na praia afetam a velocidade e direção do fluxo de vento na localidade, gerando assim danos na formação de dunas e consequentemente influênciando na posição espacial da linha de costa.

A erosão praial também se destaca como sendo um sério problema recorrente em vários países. Em certos casos, o processo erosivo pode alcançar estágios bastante elevados, em alguns trechos do litoral espanhol, por 
exemplo, a urbanização não deixou espaço suficiente para dinâmica natural costeira ocasionando prejuízos ambientais, comerciais e recreativos, (Doody, 2001). No estado de Delaware, localizado na costa leste dos Estados Unidos o enorme valor das propriedades ao longo da costa e a valorização econômica do turismo costeiro combinaram para criar um problema de gestão de recursos naturais que é particularmente difícil de resolver, pois na medida em que a indústria do turismo nessa área se expande, há o aumento de barreiras para evitar o avanço do mar devido à erosão das praias (Daniel, 2001).

Segundo Villaça (1995), o planejamento urbano desenvolvido nas últimas décadas no Brasil, vem se manifestando através de várias modalidades, as quais apresentam características distintas. Uma dessas modalidades é a que tem se manifestado através dos planos diretores das cidades.

A área de estudo localizada no bairro de Boa Viagem foi escolhida por ser uma das áreas de maior aglomeração populacional do município, além de outras particularidades é uma área costeira com características residenciais e comerciais tendo destaque o Shopping Center Recife (segundo maior centro de compras do Nordeste). Além da presença do Aeroporto Internacional dos Guararapes. Portanto, é indiscutivelmente o bairro mais atrativo para hotelaria, turismo e lazer que é potencializado por suas características residenciais.

Ao estudar uma área que sofreu e ainda sofre interferência humana, classificada como área urbanizada, destaca-se a importância do estudo temporal da mesma. A importância de investigar o uso do solo pode ser exemplificada com mais detalhes em vários trabalhos como, por exemplo, (Baumgartner \& Apfl, 2009; Boyd \& Foody, 2011; Szuster et al., 2011).

O uso do sensoriamento remoto torna-se fundamental para obtenção de dados temporais atuando como uma ferramenta poderosa para identificação dos problemas causados pelo não planejamento adequado do espaço físico destinado para urbanização, (Li et al., 2011).

Neste contexto, o presente trabalho tem como objetivo investigar a evolução do uso do solo em uma área localizada na praia de Boa Viagem (Recife/Pernambuco/Brasil). Para tanto, foram utilizadas imagens de satélite de alta resolução espacial e ortofotos para extrair informações pelo processo de vetorização, além de um levantamento topográfico pelo processo de irradiação para obtenção das posições tridimensionais de algumas feições de interesse.

\section{Área de Estudo}

Parte da concentração urbana do Recife está inserida no litoral, localizadas nas praias de Pina e Boa Viagem que totalizam aproximadamente $8,5 \mathrm{~km}$ de extensão de faixa costeira. Recife conforme dados do censo de 2010, conta com uma população de 1.537.704 habitantes e apresenta uma superfície territorial de 218,498 $\mathrm{km}^{2}$. Limitando-se ao norte com as cidades de Olinda e Paulista, ao sul com o município de Jaboatão dos Guararapes, a oeste com São Lourenço da Mata e Camaragibe, e a leste com o Oceano Atlântico. O Quadro No 1 apresenta os valores de área e população em 2010 dos municípios ao redor de Recife que somando sua população totalizam aproximadamente três milhões de habitantes.

O litoral do Recife encontra-se localizado na costa do Nordeste Brasileiro e como em muitas partes do mundo vem sofrendo os efeitos da erosão costeira provavelmente causada pelo processo de urbanização. A Figura $N^{\circ} 1$ apresenta um mapa de localização do Estado de Pernambuco no Brasil, a ampliação do Estado e em particular um polígono que define o bairro de Boa Viagem em uma imagem de satélite que é formado pelas praias do Pina (com uma área territorial $6,16 \mathrm{~km}^{2} \mathrm{e}$ população residente de 27.422 habitantes) e de Boa Viagem (com área territorial de 7,32 $\mathrm{km}^{2}$ e população residente com 100.388 habitantes) 
Quadro $N^{\circ} 1$

Área total e população dos municípios na malha urbana

\begin{tabular}{|l|r|r|}
\hline Municípios & Área $\left(\mathrm{Km}^{2}\right)$ & População (2010) \\
\hline Camaragibe & 51,194 & 144.466 \\
\hline Jaboatão dos Guararapes & 258,566 & 644.620 \\
\hline Olinda & 41,659 & 377.779 \\
\hline Paulista & 97,364 & 300.466 \\
\hline Recife & 218,498 & 1.537 .704 \\
\hline São Lourenço da Mata & 262,157 & 102.895 \\
\hline Total & 929,438 & 3.107 .930 \\
\hline
\end{tabular}

Fonte: IBGE, 2010.

Figura $\mathrm{N}^{\circ} 1$

Mapa de Localização do Bairro de Boa Viagem

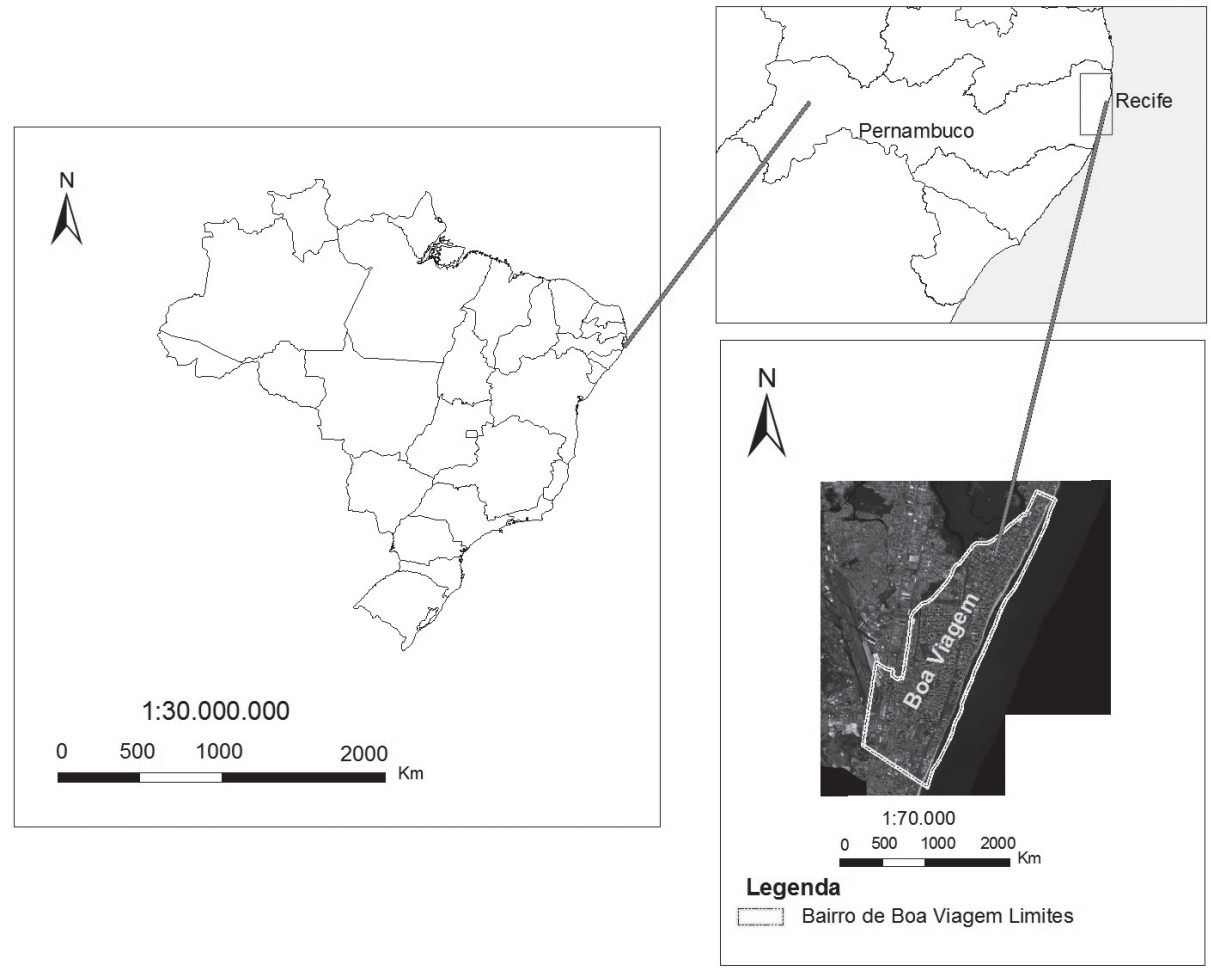

Fonte: Elaboração própria. 


\section{Características Geográficas Costeiras}

Segundo Manso et al. (2006), o litoral pernambucano foi delimitado e setorizado com base na sua situação geográfica e política em 21 municípios, distribuídos numa faixa de $187 \mathrm{~km}$. As praias são definidas em Almeida (2008), como feições geológicas temporárias e movimentadas, estando entre os sistemas físicos da superfície da terra com maior dinâmica. O processo de urbanização da praia de Boa Viagem foi acelerado nos anos 70 devido à exploração turística.

A Praia de Boa Viagem é uma praia oceânica da Cidade do Recife e se situa na zona sul fazendo parte de um conjunto paisagístico (composto por um cordão arenoso paralelo a linha de costa de orientação aproximada Norte-Sul) de ecossistemas costeiros que se estendem outros $7 \mathrm{~km}$ para o sul, ao longo da praia de Piedade (Município de Jaboatão dos Guararapes), mais detalhes em Costa et al. (2008).

Costa et al. (2008), relatam que a praia de Boa Viagem e seu segmento mais ao norte, a praia do Pina, chegaram a ser consideradas Unidades de Conservação $\left(0,58 \mathrm{~km}^{2}\right)$ pela Prefeitura da Cidade do Recife em 2000. Sem planejamento adequado a orla de Boa Viagem passou a ser explorada não só pela atividade turística, mas também pela atividade imobiliária, resultando na perda das características ambientais, mais detalhes em Silva et al. (2006). Infelizmente, nesta praia é visto um grande acúmulo de lixo principalmente nos finais de semanas e feriados, ou após períodos de chuva. A construção de uma avenida beira-mar (pistas de rolamento, calçada, mureta, quiosques, banheiros e infraestrutura de lazer) teve forte influência na impermeabilização do terreno e imobilização das dunas, podendo ter levado a um sério deslocamento do frágil balanço sedimentar agravando a erosão costeira.

A especulação imobiliária no bairro de Boa Viagem principalmente próximo a praia acelerou a verticalização e aumentou o custo de vida da população local. A verticalização da orla de Boa Viagem, e em seguida da praia de Piedade, juntamente com os assentamen- tos subnormais, foram processos rápidos e descontrolados. As construções encontram-se sobre a pós-praia, ou ocupando a maior parte dela. Restam poucos espaços vazios, que possam ser planejados para empreendimentos públicos ou privados, gerando um grande problema para sociedade, além de impactos ambientais, mais detalhes em Andrade et al. (2008).

A orla de Boa Viagem pode ser classificada como "exposta com urbanização consolidada" ou "exposta com urbanização" (Projeto Orla, 2002). Seguindo outra classificação (Smith, 1991) ela é considerada como cidade resort, ou praia altamente desenvolvida (Morgan, 1999). Esta praia apresenta diferentes graus de conservação em relação ao ambiente praial. Os recifes de arenito são responsáveis pela formação de piscinas naturais durante a baixa-mar.

A maioria dos hotéis de luxo construída na orla de Boa Viagem encontra-se em frente à maior faixa de extensão desses arrecifes, explorando a beleza cênica do local.

De acordo com a Lei de Gerenciamento Costeiro do Estado de Pernambuco sob $\mathrm{N}^{\circ} 14.258$ (2010), a faixa terrestre da Zona Costeira do Estado de Pernambuco é composta pelos municípios costeiros, subdividida em três setores dos quais será destacado o Setor Núcleo Metropolitano, composto pelos Municípios: (Recife, Jaboatão dos Guararapes, Olinda, São Lourenço da Mata, Camaragibe e Moreno). A Região Metropolitana do Recife está situada na Zona Costeira do Estado de Pernambuco, estando subordinadas direta ou indiretamente aos processos que regem a faixa de transição continente-oceano.

\section{Zoneamento urbano}

O Zoneamento é considerado e definido como um instrumento de planejamento urbano indispensável na execução do uso do solo. Predominante a um sistema legislativo (normalmente em nível municipal) visam regular o uso, ocupação e arrendamento da terra urbana por parte dos agentes de produção do espaço, tais como as construtoras, incorporadoras, proprietários de imóveis e o próprio Estado. 
A cidade do Recife possui um Plano Diretor que serve para a organização da estrutura espacial da cidade (formada pelos recursos naturais, pelo conjunto edificado, formal ou informal, pela infraestrutura e pela distribuição dos equipamentos, atividades e serviços urbanos) sua divisão por zonas, para melhor atender as necessidades especificas de cada área. A divisão por zonas deve ocorrer a partir da identificação dos problemas urbanos e do que se pretende realizar em cada área da cidade, com as condicionantes básicas de suas características físico-espaciais serem compatíveis assim como a distribuição espacial dos usos e atividades urbanas.

Segundo o Plano Diretor (2004) da cidade de Recife:

“a estruturação espacial da cidade deve considerar as características morfológicas e tipológicas do ambiente construído, respeitando a diversidade cultural. Onde o uso e a ocupação do solo deverão ser compatíveis com a oferta de infraestrutura, saneamento e serviços públicos e comunitários, levando em consideração o direito de vizinhança, a segurança do patrimônio público e privado, a preservação e recuperação do ambiente natural e construído".

O problema da verticalização da Av. Beira Mar de Boa Viagem não é justificado somente pelo seu impacto na malha urbana e dinâmica do bairro de Boa Viagem ou da cidade do Recife, mas principalmente pelo impacto natural pela proximidade à praia, tendo seu gabarito de altura maximizando os efeitos nocivos do sombreamento, dificultando ou impedindo a ventilação, além de como citado anteriormente é parte da causa do processo de erosão costeira.

\section{Linha de Costa}

A linha de costa é considerada como uma das feições geomorfológicas mais dinâmicas, do nosso planeta (Boak \& Turner, 2005; Almeida, 2008; Rocha et al., 2008). Seu monitoramento é necessário para que se possa gerenciar o ambiente costeiro, que pode sofrer erosões, resultantes da combinação de fatores naturais como: as tempestades, as correntes marítimas, mudanças sazonais e ação humana (explorações costeiras e as atividades de engenharia) (Rocha et al., 2008; Harley et al., 2011).

Em relação a essa dinâmica e definição da existência de múltiplos indicadores da linha de costa, podem ser vistos detalhes em Boak \& Turner (2005).

A falta de informações cartográficas temporais dificulta a determinação da variabilidade da linha de costa. O monitoramento da posição da linha de costa é uma informação vital para gestão do meio ambiente e faz parte do conjunto de tarefas e atividades que contribuem com o gerenciamento costeiro (Gonçalves et al., 2012).

Com a variabilidade da linha de costa é necessário considerar o sentido da escala temporal e espacial, para que assim seja mais compreensível à relação que há entre a linha de costa com as características dos limites terra-água-física, ver em Boak \& Turner (2005). Do ponto de vista físico a linha de costa corresponde simplesmente à linha interface formada entre o continente e o mar, a tentativa de delimitá-la torna-se mais complicada. Pois há variação entre várias escalas temporais (Almeida, 2008).

Visando a preservação e valorização do ambiente costeiro, a Lei de Gerenciamento Costeiro do Estado de Pernambuco sob $\mathrm{n}^{\circ} 14.258$ (2010), visa promover e apoiar a conservação, recuperação e o controle de áreas que sejam representativas dos ecossistemas da zona costeira. Como também promover um constante controle da posição da linha de costa e incentivar o desenvolvimento de atividades que respeitem as limitações e as potencialidades dos recursos ambientais.

Neste trabalho a área de estudo sofre com a erosão costeira dando indicativos que a urbanização vem avançando em direção à linha de costa.

\section{Metodologia}

Com a organização e resgate de informações cartográficas temporais foi possível criar um banco de dados geográfico para extrair informações do processo de evolução urbana. 
Em uma primeira etapa foram elaborados mapas temáticos vetoriais obtidos através de fotointerpretação de imagens no formato digital. Em seguida foi realizado um levantamento topográfico de algumas feições. A seguir são apresentados os materiais e detalhes dos procedimentos metodológicos.

O processo de vetorização para representar o uso do solo foi desenvolvido utilizando ortofotos do ano de 1974 no formato Tif e imagens orbitais do satélite Quickbird (2005). Para a interpretação das feições cartográficas e elaboração de mapas de uso do solo utilizou-se o software ArcGIS 9.3.

A Figura $N^{\circ} 2$ apresenta a ortofoto de 1974 e a imagem de satélite de 2005 fundamentais para recompor uma análise espaçotemporal, da área escolhida. Em ambas as imagens são possíveis identificar um polígono representando os limites do bairro de Boa viagem.

Equipamentos e acessórios topográficos tais como Estação Total Trimble 3306 DR, tripé de alumínio, trena, prisma e bastão foram utilizados no levantamento topográfico planialtimétrico para se obter posições tridimensionais de algumas feições. Os dados finais foram calculados e processados com o auxílio dos softwares Microsoft ${ }^{\circledR}$ Excel, AutoCAD ${ }^{\circledR}$, Google Sketchup e Google Earth.

Para a realização do mapeamento de uso do solo, foi necessário inicialmente delimitar uma área que fosse coincidente nas duas imagens (ortofoto e imagem de satélite).

A área escolhida é formada pelas avenidas mais conhecidas do Bairro de Boa Viagem: Avenida Domingos Ferreira, Avenida ConseIheiro Aguiar, Avenida Boa Viagem, Avenida Barão de Souza Leão além das Ruas: Dr. Nilo de Câmara, Coronel Sérgio Cardeal, Petrolina, dos Navegantes e Setúbal.

Destaca-se que foram tomados os devidos cuidados para deixar as imagens no mesmo sistema geodésico de referência.

O software ArcGIS 9.3, foi utilizado para efetuar a vetorização de elementos de interesse possibilitando assim uma análise quantita-

Figura $\mathrm{N}^{\circ} 2$

Limite do Bairro de Boa Viagem (1974 e 2005)
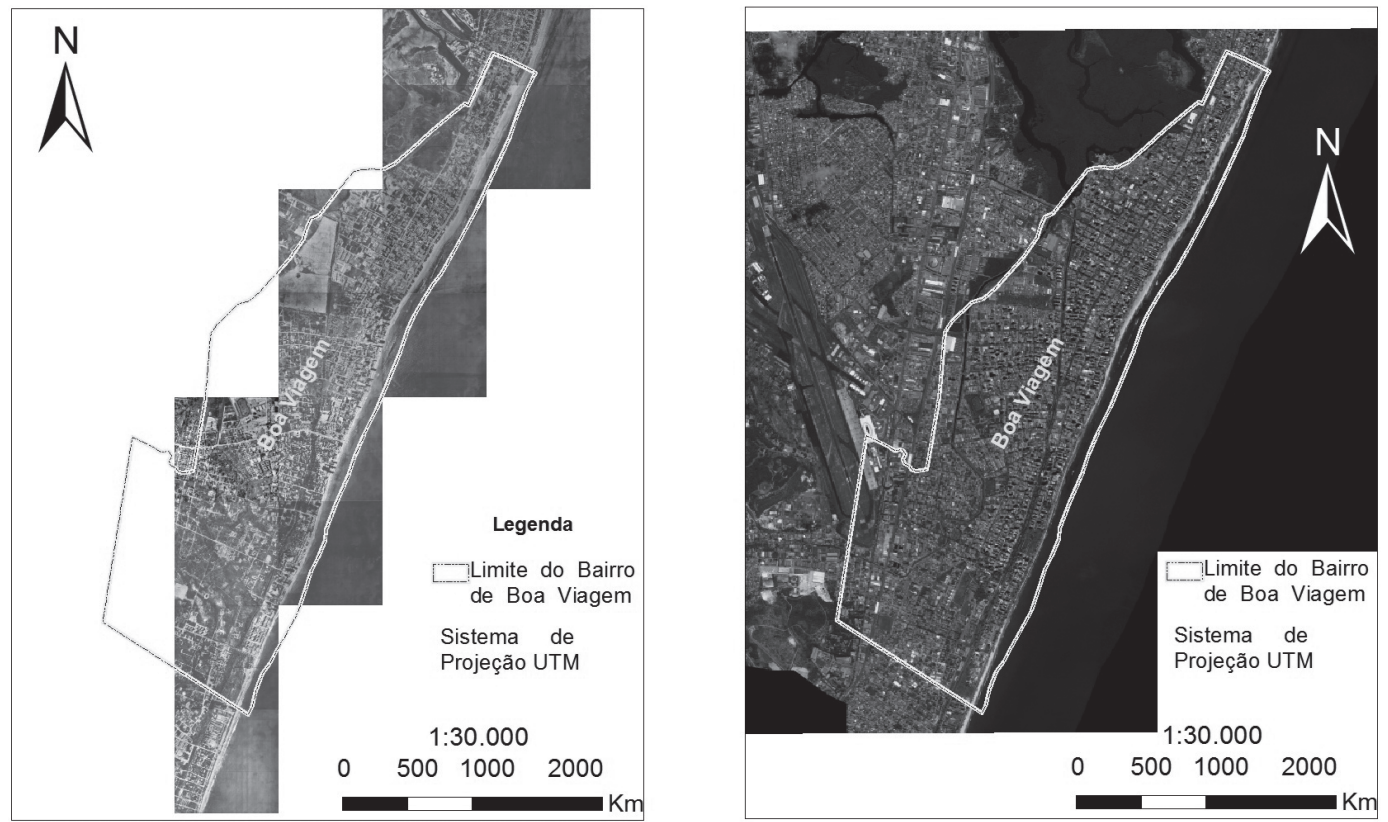

Fonte: Elaboração própria. 
tiva. Para cada classe foram criados shapefiles (*shp), inseridos através do ArcCatalog dentro de um geodatabase.

O próximo passo realizado foi selecionar as classes de interesse para a criação dos mapas temáticos temporais. Nesta etapa foram planejados os tons de cores para representar as classes levando em consideração o tipo de dados classificados como qualitativos. Sendo assim foram vetorizadas as seguintes classes apresentadas com suas descrições no Quadro $\mathrm{N}^{\circ} 2$.
No caso do levantamento topográfico, foi realizado o planejamento dos elementos a serem mapeados, para geração dos modelos tridimensionais.

O procedimento técnico utilizado para o levantamento topográfico consistiu na instalação do equipamento topográfico (estação total) em um local onde foi possível irradiar os pontos de interesse e efetuar as observações de ângulos (zenitais e horizontais) e distâncias, para a realização do processamento dos dados e cálculo das coordenadas tridimensionais. As coordenadas oriundas do levanta-

Quadro No 2

Classe selecionada e respectiva descrição

\begin{tabular}{|l|l|}
\hline Classe & Descrição \\
\hline Eixo dos logradouros & Vielas, avenidas e ruas \\
\hline Solo exposto & Locais sem vegetação, inexistência de construção (quarteirões) \\
\hline Edificações & Casas, prédios, edifícios, ou seja, tudo em alvenaria e respectivo \\
\hline Vegetação & Matas abertas ou fechadas, baixa ou alta e mangues \\
\hline Linha de costa & $\begin{array}{l}\text { Considerou-se a linha instantânea de água captada na tomada da cena } \\
\text { entre o continente e o oceano }\end{array}$ \\
\hline Faixa de areia & Areia exposta após a linha de costa e oceano \\
\hline Canais abertos & Esgoto ao longo de ruas e avenidas do Bairro de Boa Viagem \\
\hline
\end{tabular}

Fonte: Elaboração própria desenvolvida através da classificação dos dados qualitativos

mento foram exportadas para o software Auto $C A D^{\circledR}$, e posteriormente foram utilizados os recursos do Google Sketchup e Google Earth.

\section{Resultados e Discussão}

Na Figura $N^{\circ} 3$, são apresentados os resultados obtidos através do levantamento em campo no formato tridimensional conforme a sequência de softwares utilizados onde em um primeiro momento os dados coletados em campo são representados no AutoCAD no formato $3 \mathrm{D}$, Figura $\mathrm{N}^{\circ} 3(\mathrm{a})$, posteriormente são exportados para o Google Sketchup, Figura № 3(b), e por fim são visualizados no Google Earth Figura № 3(c).
A Figura $\mathrm{N}^{\circ} 4$ representa os mapas de uso do solo obtidos para os anos de 1974 e 2005, respectivamente. Em uma fotointerpretação, observa-se que em 1974, na área delimitada, havia construções de casas baixas, não existia nenhum dos edifícios tomados como referência para fazer a simulação de sombras das edificações, a vegetação era fechada e na faixa de areia havia dunas com vegetação costeira. Em 2005, as construções passam para edifícios ocupando o espaço que antes era formado por casas baixas e vegetação, na faixa de areia desaparecem as dunas e aparece a plantação de coqueiros, além da implantação de quiosques e construção de quadras de tênis. 
Figura $N^{\circ} 3$

Visualização do mapeamento (a) AutoCAD, coordenadas do levantamento topográfico (b) Goog/e Sketchup, visualização 3D e simulações de sombra (c) Goog/e Earth visualização das edificações sobre uma imagem de satélite.

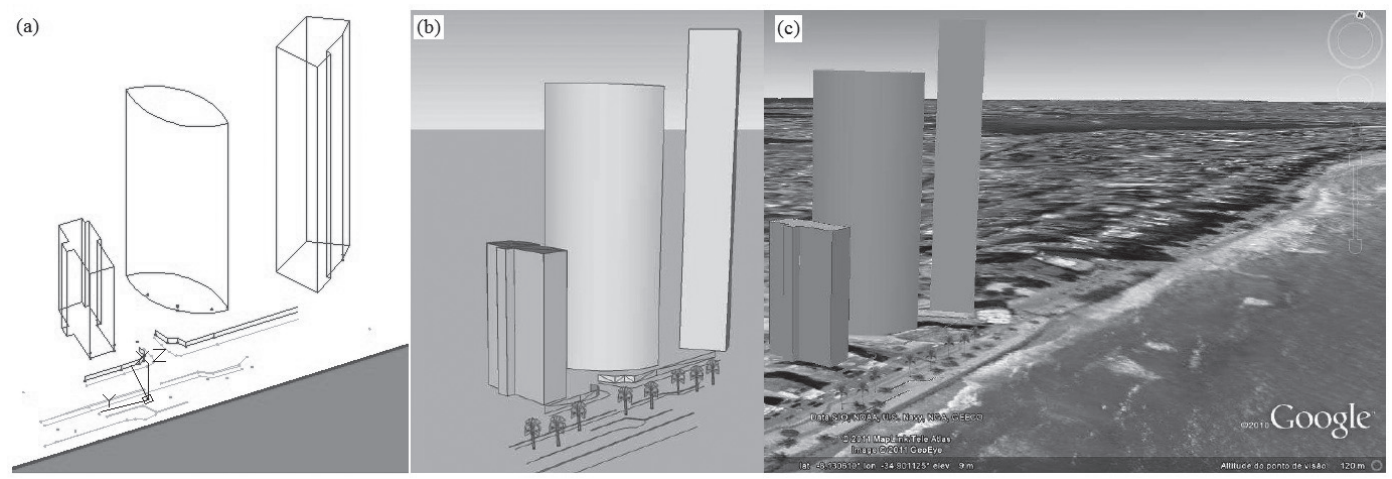

Fonte: Elaboração própria desenvolvida através do levantamento topográfico

Figura $\mathrm{N}^{\circ} 4$

Mapas Temáticos temporais da área de estudo (1974 e 2005)
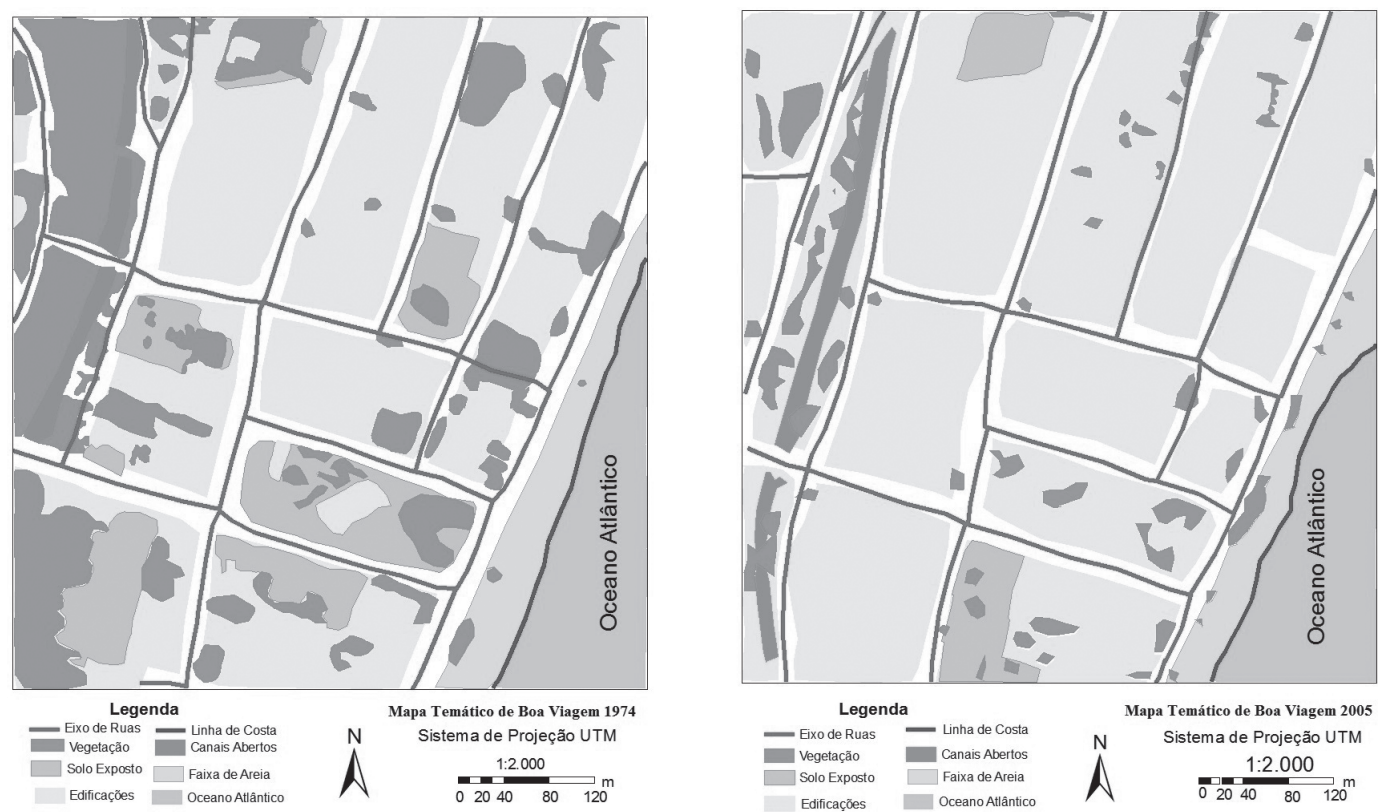

Fonte: Elaboração própria desenvolvida pelo processo de vetorização

Numa comparação visual dos mapas temáticos obtidos na Figura $\mathrm{N}^{\circ} 4$ observa-se que em 1974 a área de vegetação é maior que em 2005, sendo que houve um aumento nas edificações no decorrer do tempo. Perce- be-se também que a faixa de areia na praia aparentemente era maior em 1974. Outra ocorrência verificada é a diminuição da classe nomeada como solo exposto no decorrer do tempo, dando lugar a novas construções. 
Quadro No 3

Cálculo de área e percentual do uso do solo - 1974 e 2005

\begin{tabular}{|l|r|r|r|r|}
\hline Ano & \multicolumn{2}{|c|}{1974} & \multicolumn{2}{c|}{2005} \\
\hline Classe & Área $\left(\mathrm{m}^{2}\right)$ & Percentual $(\%)$ & Área $\left(\mathrm{m}^{2}\right)$ & Percentual $(\%)$ \\
\hline Vegetação & 38.422 & 21 & 10.312 & 6 \\
\hline Solo Exposto & 16.344 & 9 & 5.618 & 3 \\
\hline Edificações & 67.059 & 36 & 108.018 & 2 \\
\hline Canais Abertos & 2.421 & 1 & 4.059 & 31 \\
\hline Demais Feições & 60.665 & 33 & 56.904 & 58 \\
\hline
\end{tabular}

Fonte: Elaboração própria obtida através do processo de fotointerpretação e vetorização

Verifica-se também que existem indícios visuais de recuo da linha de costa, além dos canais abertos que aumentaram ao longo do tempo.

Através dos mapas temáticos obtidos foi possível quantificar a área e o percentual para cada classe selecionada. A Quadro № 3 apresenta esses dados numéricos. Destaca-se que a área total delimitada para estudo representa um espaço de $184.911 \mathrm{~m}^{2}$.

Analisando os dados obtidos na Quadro $N^{\circ} 3$, verifica-se que em 1974 a classe edificações representava 36\% já em 2005 ela passou para $58 \%$. Todo esse aumento influi diretamente na diminuição de espaços com vegetação, pois em 1974 a classe de vegetação representava uma área de $38.422 \mathrm{~m}^{2}$ passando para $10.312 \mathrm{~m}^{2} \mathrm{em} 2005$.

Nesse contexto, observa-se que os tipos de domicílios variaram muito, onde antes existiam as classes casas e vegetações passaram no decorrer do tempo para edifícios. É possível observar que a classe solo exposto no decorrer do tempo vem diminuindo e dando espaço para a classe edificações.

Outro estudo realizado diz respeito a simulações para observação das sombras gerada pelas edificações a partir do levantamento topográfico.

Nas Figuras $\mathrm{N}^{\circ} 5, \mathrm{~N}^{\circ} 6$ e $\mathrm{N}^{\circ} 7$ são representados as simulações geradas de três edifícios em relação a distância da linha de costa e a projeção de sombra em determinadas épocas e horários do ano.

O Quadro $N^{\circ} 4$ representa características dos edifícios mapeados apresentando o ano de construção, nome da edificação, número de andares e altura da edificação.

Quadro $N^{\circ} 4$

Características das edificações mapeadas

\begin{tabular}{|l|r|r|r|}
\hline Nome do Edifício & Ano de Construção & Número de andares & Altura (m) \\
\hline Ed. Illha de Thasos & 1980 & 16 & 59 \\
\hline Ed. Luis Dias Lins & 2011 & 36 & 122 \\
\hline Ed. Maria Ângela de Lucena & 2011 & 46 & 148 \\
\hline
\end{tabular}

Fonte: Elaboração própria. 
Na Figura $N^{\circ} 5$ é possível verificar a distância entre a posição espacial da linha de costa em relação ao inicio das edificações, observa-se que esta distância corresponde a $38,52 \mathrm{~m}$.

Todas as simulações estão levando em consideração a preia-mar observada pela posição da linha de costa na Orla de Boa Via- gem na data do levantamento topográfico na frente dos três edifícios.

Além da análise em relação às construções próxima a linha de costa buscou-se verificar a sombra que os edifícios projetam na faixa de areia em determinadas épocas e horários do ano, realizadas em: janeiro de

Figura $N^{0} 5$

Distância da linha de costa ao início das edificações

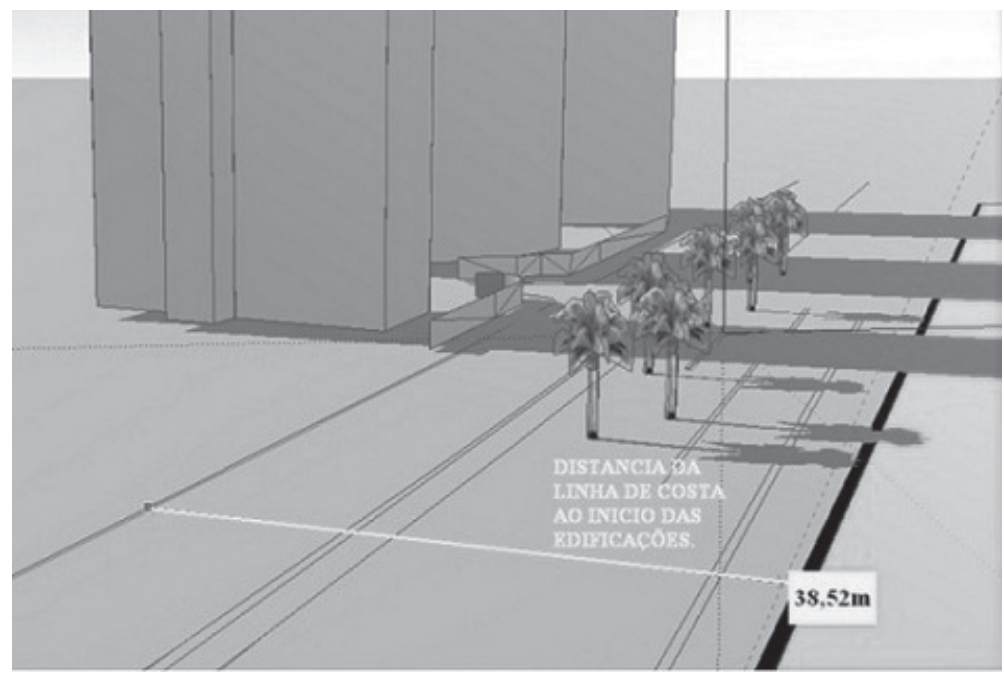

Fonte: Elaboração própria.

Figura $N^{\circ} 6$

Janeiro de 2011 às $15 \mathrm{~h}$

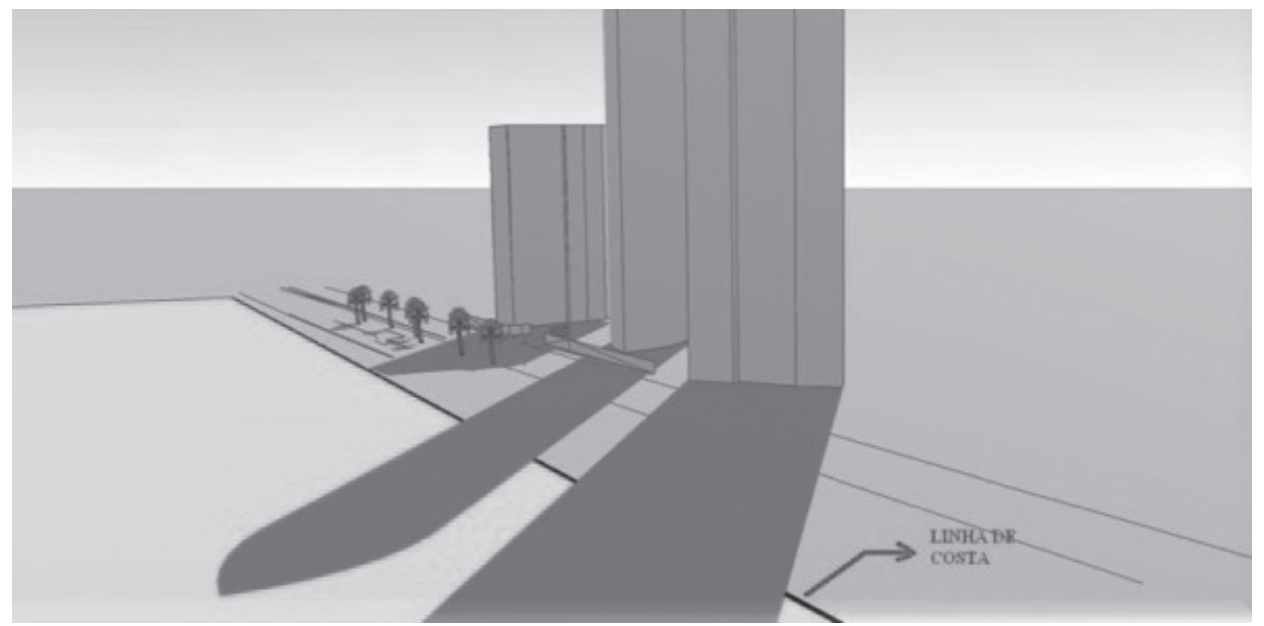

Fonte: Elaboração própria desenvolvida através do levantamento topográfico 
Figura $\mathrm{N}^{\circ} 7$

(a) Agosto de 2011 às 15 horas; (b) Abril de 2011 às 14 horas

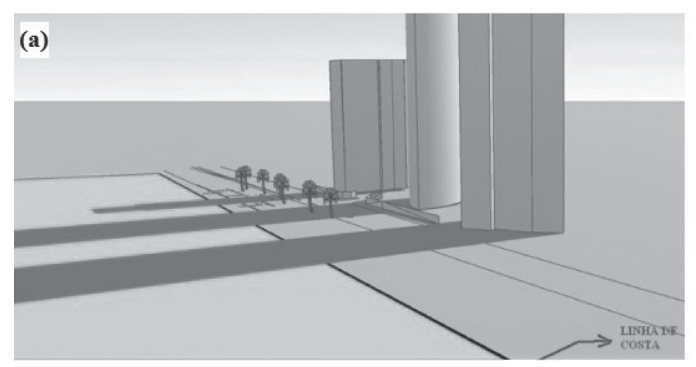

Fonte: Elaboração própria.

2011 às 15h, abril de 2011 às 14h, agosto de 2011 às $15 \mathrm{~h}$.

Analisando as Figuras $N^{\circ} 6, \mathrm{~N}^{\circ} 7$ (a) e $\mathrm{N}^{\circ}$ 7 (b), observa-se que as sombras dos edifícios chegam até a areia, isto prejudica a dinâmica praial, pois a área de praia é uma área que demanda sol para o lazer da população.

Na Figura $N^{\circ} 7$ (b) foi feita uma simulação em horário distinto em relação às outras tomadas, para verificar a projeção que a sombra faz antes das 15 horas, mas infelizmente já há sombra antes desse horário.

\section{Conclusões e Considerações Finais}

A praia é um dos grandes pontos de lazer atrativos na cidade do Recife, mas encontrase comprometido por conta da falta de espaço de areia para permanência quando a maré está alta. Outro fator prejudicial à dinâmica praial é a sombra provocada pelas edificações, pois a área de praia é uma área que demanda sol e antes das 15 horas já há sombra, como apresentado nas imagens da simulação.

Em uma análise temporal considerando os anos de 1974 e 2005 como referência, ou seja, 31 anos de evolução do espaço foi possível quantificar que a classe vegetação passou de $21 \%$ para $6 \%$, e as edificações de $36 \%$ para $58 \%$ sendo que construções consideradas como baixas se transformaram em edifícios residenciais retratando o processo de expansão urbana vertical.

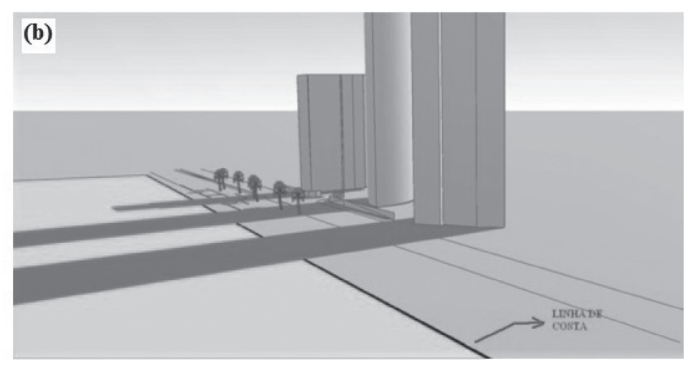

Outro resultado importante foi à determinação da posição da linha de costa na área selecionada, sendo possível mapeá-la e confrontá-la com a Lei de gerenciamento costeiro que determina que a distância mínima da linha de costa ao inicio das edificações deve ser de 33 metros, e no local a distancia é de 38,52 metros. Entretanto, as construções entre a edificação e a linha de costa, que são a Avenida e o calçadão, não dão o espaço mínimo necessário para a movimentação normal das águas. Isso gera um grande problema que é mutuo, pois a configuração urbana já está consolidada e prejudica a dinâmica da praia e da maré. A contenção do mar, por conta do mau planejamento da cidade, se torna um problema, pois exige cuidados constantes.

$\mathrm{Na}$ escolha de alguns quarteirões do Bairro de Boa Viagem, para desenvolvimento do estudo temporal foram elaborados mapas temáticos onde se observou como ocorre à aceleração do crescimento urbano.

A verticalização está presente na sociedade contemporânea e causa impactos de vizinhança, considerando o sistema de transportes, meio ambiente, infraestrutura básica, estrutura socioeconômica e os padrões funcionais e urbanísticos, além da questão da ventilação e iluminação.

Através da metodologia utilizada para identificar as características do zoneamento urbano, destaca-se que a fonte de informação cartográfica, serviu como ferramenta fundamental para as análises de informações espaciais. 
Ainda existem muitas questões que precisam ser analisadas e respondidas no que se refere ao diagnóstico e temas ligados ao crescimento populacional extremamente superior a capacidade de absorção do sistema econômico e dos equipamentos funcionais urbanos.

Baseado na revisão da literatura e no conhecimento da realidade encontrada no município de Recife-PE, mais precisamente no Bairro de Boa Viagem, indicam-se alguns pontos que podem ser trabalhados em pesquisas futuras, de modo a dar continuidade no assunto proposto, sendo assim sugere-se ampliar a área de estudo e aplicar novas técnicas semi-automatizadas direcionadas a objetos para interpretação e classificação de imagens digitais.

Outra perspectiva seria a utilização de dados LASER scanner aerotransportado, também conhecido como LIDAR (Light Detection and Ranging). Nos últimos anos, a tecnologia LIDAR, vem se consagrando como alternativa viável à aquisição automática do MDT (Modelo Digital do Terreno) em mapeamentos de grande escala e alta acurácia (Pacheco et al. 2011).

\section{Referências bibliográficas}

ALMEIDA, H.R.R.C. Séries temporais de imagens suborbitais e orbitais de alta resolução espacial na avaliação da morfodinâmica praial no município do Cabo de Santo Agostinho $-P E$. Recife: Editorial da Universidade, 2008. Disponível na Internet: http://www. ufpe.br/cgtg/dissertacoes.html.

AMARAL, R. \& RIBEIRO, R. R. Desastres naturais conhecer para prevenir: Inundações e Enchentes. São Paulo: Instituto Geológico, 2009. Disponível na Internet: http://www. igeologico.sp.gov.br/downloads/livros/DesastresNaturais.pdf.

ANDRADE, B.; ARENAS, F. y GUIJÓN, R. Revisión crítica del marco institucional y legal chileno de ordenamiento territorial: el caso de la zona costera. Revista de Geografía Norte Grande, 2008, No 45, p. 23-48.

BAUMGARTNER, M.F. \& APFL, G. M. Remote Sensing and Geographic Information
Systems. Journal of Hydrological Sciences, 2009, No 41, p. 593-607.

BOAK, E.H. \& TURNER, I.L. Shoreline Definition and Detection: A Review. Journal of Coastal Research, 2005, № 21, p. 688-703.

BOYD, D. S. \& FOODY, G.M. An overview of recent remote sensing and GIS based research in ecological informatics. Journal of Ecological Informatics, 2011, Nº 6, p. 25-36.

COSTA, M.F.; ARAUJO, M.C.B.; CAVALCANTI, J.S.S. \& SOUZA, S.T. Verticalização da Praia da Boa Viagem (Recife, Pernambuco) e suas Consequências Socioambientais. Revista da Gestão Costeira Integrada, 2008, N ${ }^{\circ}$ 8, p. 233-245. Disponível na Internet: http:// www.aprh.pt/rgci/pdf/RGCl -128_Ferreira-daCosta.pdf.

DANIEL, H. Replenishment versus retreat: the cost of maintaining Delaware's beaches. Ocean \& Coastal Management, 2001, $N^{\circ} 44$, p. 87-104, 2001.

DOODY, J. P. Shoreline management conservation, managementor restoration? National Coastal Consultants, 2001, p. 407-419.

FAGGI, A. M. \& DADON, J. Vegetation changes associated to coastal tourist urbanizations. Multequina - Latin American Journal of Natural Resources, 2010, No 19, p. 53-76.

GONÇALVES, R.M.; AWANGE, J.; KRUEGER, C.P.; HECH, B. \& COELHO, L.S. A comparison between three short-term shoreline prediction models. Ocean \& Coastal. Management, 2012, Vol. 69, p. 102-110.

HAPKE, C. \& PLANT, N. Predicting coastal cliff erosion using a Bayesian probabilistic model. Journal of Marine Geology, 2010, $\mathrm{N}^{\circ}$ 278, P. 140-149.

HARLEY, M.D.; TURNER, I.L.; SHORT, A. D. \& RANASINGHE, R. Assessment and integration of conventional, RTK-GPS and image-derived beach survey methods for daily to decadal coastal monitoring. Journal of Coastal Engineering, 2011, № 58, p.194-205.

IBGE (Instituto Brasileiro de Geografia e Estatística). Mapa de distribuição da popu- 
lação 2000. Disponível em Internet: http:// www.ibge.gov.br/home/geociencias/geografia/ mapas_doc1.shtm

IBGE (Instituto Brasileiro de Geografia e Estatística). Dados estatísticos das cidades do Estado de Pernambuco 2010. Disponível em Internet: http://www.ibge.gov.br/cidadesat/ link.php?codmun $=261370$

LEI DE GERENCIAMENTO COSTEIRO DO ESTADO DE PERNAMBUCO. Lei $\mathrm{N}^{\circ}$ 14. 258, de 23 de dezembro de 2010. Disponível na Internet: http://www.cprh.pe. gov.br/ARQUIVOS_ANEXO/Lei\%20Est\%20 14258;141010;20101228.pdf

KRELLENBERG, K.; HÖFER, R. y WELZ, J. Dinámicas recientes y relaciones entre las estructuras urbanas y socioeconómicas en Santiago de Chile: el caso de Peñalolén. Revista de Geografía Norte Grande, 2011, Nº 48, p. 107-131.

LI, C.; YIN, J. \& LIU, L. Research Overview on Urban Land Use Change Based on Remote Sensing Images. International Journal of Environmental Science and Development, 2011, Vol.2, N ${ }^{\circ}$ 1. Disponivel na Internet: http://www.ijesd.org/papers/95-D505.pdf

MANSO, V.A.V.; COUTINHO, P.N.; GUERRA, N.C. \& JUNIOR, C.F.A. S. Erosão e Progradação do Litoral Brasileiro: Pernambuco. Laboratório de Geologia e Geofísica Marinha - LGGM. Recife: Editorial da Universidade Federal de Pernambuco, 2006. Disponível na Internet: http://www.mma.gov.br/ estruturas/sqa_sigercom/_publicacao/78_publicacao12122008091035.pdf

MORGAN, R. Preferences and priorities of Recreational Beach Users in Wales, UK. Journal of Coastal Research, 1999, No 15, p. 653- 667. Disponível na Internet: http://www.jstor.org/stable/4298982.

NORDSTROM, K.F. \& JACKSON, N.L. Effects of a high rise building on wind flow and beach characteristics at Atlantic City, NJ, USA. Ocean \& Coastal Management, 2010, No 39, p. 245-263.

NOVACK, T. \& KUX, H.J.H. Urban land cover and land use classification of an infor- mal settlement area using the open-source knowledge-based system InterIMAGE. Journal of Spatial Science, 2010, p. 23- 41.

PACHECO, A.P.; CENTENO, J.A.S.; ASSUNÇÃO, M.G.T. \& BOTELHO, M.F. Classificação de pontos LIDAR para geração do MDT. Boletim de Ciências Geodésicas, 2011, Vol. 17, No 3, p. 417-438. Disponível na Internet: http://ojs.c3sl.ufpr.br/ojs2/index.php/ bcg/article/viewArticle/24599

PLANO DIRETOR DO RECIFE, 2004. Disponível na Internet: http://www.recife.pe.gov. $\mathrm{br} / \mathrm{pr} / \mathrm{sec}$ lanejamento/planodiretor/

POLIDORO, M.; TAKEDA, M.M.G. \& BARROS, O.N.F. Análise temporal do processo de conurbação na região de Londrina-PR por meio de imagens Landsat. Revista Geográfica Acadêmica, 2009, Vol. 3, No 1, p. 70-77. Disponível na Internet: http://www. rga.ggf.br/index.php?journal=rga\&page $=$ article\&op=viewFile\&path\%5B\%5D=58\&path $\% 5 \mathrm{~B} \% 5 \mathrm{D}=48$

PROJETO ORLA. Projeto de gestão integrada da orla marítima. Brasília: Ministério do Meio Ambiente e Ministério do Planejamento, Orçamento e Gestão, 2002. Disponível na Internet: http://www.planejamento.gov. br/secretarias/upload/Arquivos/spu/publicacao/081021_PUB_ProjOrla_fundamentos.pdf

ROCHA, C.P.; ARAÚJO, T.C.M. \& MENDONÇA, F.J.B. Aplicação de técnicas de posicionamento GPS tridimensional para localizar linhas de costa: estudo de caso na praia de Boa Viagem, Recife/PE, Brasil. Revista da Gestão Costeira Integrada, 2008, № 8, p. 127-137. Disponível na Internet: http://www. aprh.pt/rgci/pdf/RGCl-139_Rocha.pdf

SÁNCHEZ, R. La debilidad de la gestión del riesgo enlos centros urbanos. El caso del Área Metropolitana de Santiago de Chile. Revista de Geografía Norte Grande, 2010, No 47, p. 5-26.

SILVA, J.S.; BARBOSA, S.C.T.; LEAL, M.M.V.; LINS, A.R. \& COSTA, M. F. Ocupação da praia da Boa Viagem (Recife/PE) ao longo de dois dias de verão: um estudo preliminar. Pan-American Journal of Aquatic Sciences, 2006, № 1, p. 91-98. Disponível na 
Internet: http://www.panamjas.org/pdf_artigos/PANAMJAS_1(2)_91-98.pdf

SMITH, R. A. Beach resorts: A model of development evolution. Landscape and Urban Planning, 1991, № 21, p. 189-210.

SZUSTER, B.W.; CHEN, Q. \& BORGER, M. A comparison of classification techniques to support land cover and land use analysis in tropical coastal zones. Journal of Applied Geography, 2011, № 31, p. 525-532.

TEIXEIRA, J.C. \& HELLER, L. Fatores ambientais associados à diarreia infantil em áreas de assentamento subnormal em Juiz de Fora - Minas Gerais. Revista Brasileira de Saúde Materna Infantil Recife, 2005, № 5, p.
449-455. Disponível na Internet: http://www. bvsde.paho.org/CDGDWQ/CasosEstudiosPSA/RBSMI\%20Teixeira\%20e\%20Heller.pdf

TOMINAGA, L.K. Desastres naturais conhecer para prevenir: Escorregamento. São Paulo: Instituto Geológico, 2009. Disponível na Internet: http://www.igeologico.sp.gov.br/ downloads/livros/DesastresNaturais.pdf

VILLAÇA, F. Dilemas do Plano diretor: Uma contribuição para a história do planejamento urbano no Brasil (no prelo) e Crise do planejamento urbano. Revista Perspectiva, 1995, Vol. 9, № 2. Disponível na Internet: http://www.ongcidade.org/site/arquivos/artigos/dilemas436f9e94d59fb.pdf 